FedUni ResearchOnline

http://researchonline.federation.edu.au

This is an Accepted Manuscript of an article published by Taylor \& Francis in International Journal of Inclusive Education on 18/09/2015, available online:

http://doi.org/10.1080/13603116.2015.1079273 


\title{
"Low income doesn't mean stupid and destined for failure:” Challenging the deficit discourse around students from low SES backgrounds in higher education
}

\author{
Dr Jade McKay* \\ Research Fellow \\ Faculty of Business and Law \\ Deakin University, Australia \\ 221 Burwood Hwy, Burwood, VIC 3125 \\ Phone: 0431176010 \\ Email: jade.mckay@,deakin.edu.au \\ *Corresponding Author \\ Professor Marcia Devlin \\ Deputy Vice-Chancellor (Learning and Quality) \\ Federation University Australia \\ PO Box 3191, Gippsland Mail Centre, Vic 3841 \\ Phone: 61351226211 \\ Email: dvc.learning@federation.edu.au
}

\begin{abstract}
The discourse around students from low SES backgrounds often adopts a deficit conception in which these students are seen as a "problem" in higher education. In light of recent figures pointing to an increase in the number and proportion of these students participating in higher education (Pitman 2014) and an absence of evidence to support deficit thinking, this deficit discourse requires re-examination. Qualitative data from 115 interviews carried out across six Australian universities as part of a national study reveals that, contrary to the conception of these students as a "problem", students from low socioeconomic backgrounds demonstrate high levels of determination and academic skills and that they actively seek high standards in their studies. This paper critically examines deficit conceptions of these students, drawing on findings from qualitative interviews with 89 successful students from low socioeconomic backgrounds and 26 staff members recognised as exemplary in their provision of teaching and support of students from low socioeconomic backgrounds. Drawing on these findings, this paper challenges the deficit discourse and argues for a more affirmative and nuanced conception of students from low socioeconomic backgrounds.
\end{abstract}

Keywords: low socioeconomic students; higher education; deficit discourse; widening participation; deficit thinking

\section{Acknowledgements}

The authors gratefully acknowledge the funding for this study provided by the Australian Commonwealth Office for Learning and Teaching, thank our fellow researchers and all of those 
who participated in the research and thank two anonymous reviewers who helped us sharpen and strengthen the paper.

\section{“Low income doesn't mean stupid and destined for failure:” Challenging the deficit discourse around low SES students in higher education}

\section{Introduction}

Literature and the discourse around students from low socioeconomic (SES) backgrounds in higher education often adopts a deficit conception in which these students are associated with low entrance scores, decreasing standards and academic struggle and failure (Smit 2012; Devlin 2013). The extant research and populist media commentaries, in particular, suggest that the challenges and failures experienced by students from low SES are the "fault" of students who are deemed "in deficit" (Devlin 2013) and seen as not belonging in universities (Smit 2012). Australian government data from 2013 indicates that the number and proportion of commencing students from low SES backgrounds in Australian higher education increased by 7.4 per cent from 2012 (Pitman 2014; Department of Education 2013). These figures necessitate a rethink of how students from low SES backgrounds in higher education are commonly conceptualized. As Gale (2011) posits, the widening participation push from government and in the higher education sector compels universities to develop "a new regard" for the diverse students entering their hallowed halls.

From individual interviews with 89 successful students from low SES backgrounds and 26 university staff undertaken as part of a national study, it was found that, contrary to the idea that these students are somehow in deficit, students from low SES backgrounds make a valuable contribution and are an asset to higher education. This paper proposes a more nuanced approach to the complexities of the presence and experience of these students in universities; one that prioritises the agency of students and challenges deficit conceptions. It stresses the need for educators and institutions to be aware of the hegemonic practices and discourses at play in universities and their negative consequences for marginalised groups (Shields, Bishop and Mazaei 2005; Boughey 2007; Swanson 2002; Marshall and Case 2010).

After providing an overview of the deficit-discourse in the literature, the parameters of the national study from which this paper emerged are outlined, followed by a discussion of the findings from this study and concluding comments.

\section{Deficit conceptualisations of students from low SES backgrounds in the literature}

Please reference as: McKay, J. and Devlin, M. (2015). "Low income doesn't mean stupid and destined for failure:" Challenging the deficit discourse around low SES students in higher education. International Journal of Inclusive Education. DOI: 10.1080/13603116.2015.1079273 


\section{The deficit discourse}

Devlin (2013) suggests that while there is literature on the positive elements of success pertaining to students from low SES backgrounds that concentrates on their resilience (Morales 2000), self-efficacy (Vuong, Brown-Welty and Tracz 2010) and high levels of motivation (McKavanagh and Purnell 2007), it is limited. Research and statistics abound on the lower educational achievements, aspirations and completion rates of students from low SES backgrounds in higher education (Margison 2008; Clare 1999; Tinto 2003; Dibben 2006; Hahs-Vaughan 2004). The literature shows that students from low SES backgrounds are associated with lower participation rates (Western, McMillan and Durrington 1998; James 2002), low entrance scores (Teese and Polesel 2003), lower aspirations (Commonwealth of Australia 2010), academic failure (Clare 1999), and as being as a "problem" in higher education (Smit 2012). Leathwood and O'Connell (2003) claim that the widening participation agenda is surrounded by a "discourse of "dumbing down" and lowering standards' (599) (also see Susanti 2011). This view is certainly apparent in the work of various theorists (see Furedi 2004; Hayes 2003) who, according to Haggis (2006), "blame" students for being 'incapable of coping with the critical challenges of conventional higher education' (523). In their extensive canvassing of the research, Shields, Bishop and Mazawi (2005) found such thinking is a pathologizing practice engendering the continued marginalisation of a group 'not treated as equal partners, capable of agency or selfdetermination' (x).

The terminology used in relation to non-traditional students is itself problematic, positioning students as "lacking" and a "problem". Based on her work in the South African higher education context, Smit (2002) delineates the problematic nature of this terminology:

The dominant thinking in higher education... attempts to understand student difficulty by framing students and their families of origin as lacking the academic, cultural and moral resources necessary to succeed in what is presumed to be a fair and open society. Much of the discussion around these topics concentrates on some aspect of deficiency: those who do not succeed in higher education fail because of some internal shortcoming (e.g. cognitive or motivational) or some external weakness linked to the student (e.g. cultural or familial background). The terminology used contributes to the deficit discourse: students are referred to in terms of what they are not: not traditional, not prepared for higher education, not in a position of privilege or advantage (emphasis added).

Drawing on the work of Devlin (2013), we argue that the deficit conceptualisation makes these students victims of discrimination that can impede their progression and success. Others agree, claiming that such thinking is fundamentally detrimental to the success of students (Shields, Bishop and Mazawi 2005; Reay, David and Ball 2005; Ford et al. 2002). Reay, David and Ball (2005) and Bourdieu (2004) respectively view higher education systems and policies as key components of the social mechanisms which 'reproduce unequal access to, and outcomes from, education for students from low SES backgrounds' (Bok 2010, 164). Research by Ford et al. (2002) reveals that, 'Reactions to differences among students manifest themselves in various ways, and they exert a powerful influence in educational

Please reference as: McKay, J. and Devlin, M. (2015). "Low income doesn't mean stupid and destined for failure:" Challenging the deficit discourse around low SES students in higher education. International Journal of Inclusive Education. DOI: 10.1080/13603116.2015.1079273 
settings' (53). Others have similar findings (see for example, Bishop and Glynn 1999; Shields, Bishop and Mazawi 2005; Wagstaff and Fusarelli 1995; Valencia 1997; Swadener and Lubeck 2003). "Difference" is all-too often associated with deficit, dysfunction and disadvantage and thus needs to be overhauled if students from minority groups are to succeed.

Exploring the implications of deficit thinking, Smit (2012) claims that it 'allows generalisations about student ability to be made and supports a laziness to grapple with the complex issues around student difficulties. In the process, people who are already disenfranchised are labelled and further stigmatised' (372). The deficit discourse also informs teachers' lowered expectations of non-traditional students which can impact on teaching practices (Ford et al. 2002; Smit 2012). Swanson (2002) and Smit (2012) comment on the danger to sound pedagogic practices of deficit thinking, when certain inaccurate "truths" about non-traditional students inform the learning context. Valencia (1997), in his seminal text, The Evolution of Deficit Thinking, explains the impact of deficit thinking can include that students from low SES backgrounds are: more often suspended; subjected to greater disciplinary action; segregated; under-identified as gifted or talented; more frequently referred to "remedial" or "special" programs; blamed when they fail on account of their 'limited intellectual abilities, linguistic shortcomings, lack of motivation to learn and immoral behaviour' (2). According to Swanson (2002), this is economic disadvantage being recontextualised into "pedagogic disadvantage".

The deficit discourse also results in non-traditional students being viewed as "other" compared with more traditional student cohorts which, Webb (1997) argues, represents 'the norm against which the others are judged and may be found wanting' (68). This "othering" of non-traditional students is explored by Smit (2012), who explains:

These students arrive at higher education institutions and are told...that they stand very little chance of succeeding, that they are lacking... and that they have to "catch up". They are marked and separated from the "mainstream" by virtue of their deficiency, and their "other-ness" is reinforced. In these ways students are in effect alienated from the very system they have worked so hard to be part of. (373)

It is precisely in the "othering" and alienation of non-traditional students that higher education institutions run the risk of reproducing the 'education stratification of societies' (Smit 2012, 378). Exploring the contexts, cultures, and structures of the education systems within which three groups of students-Bedouin, Maori, and Navajo-have been marginalised, Shields, Bishop and Mazawi (2005) developed a cross-cultural analysis that examines ways in which social injustice and pathologies of practice may be overcome. Based on their large-scale study, Shields et al. (2005) found a deficit discourse can predispose some students to 'become lower achieving, timid or aggressive, reluctant, disengaged' (1). Deficit thinking is thus both 'pervasive and destructive' (Shields, Bishop and Mazawi 2005, 1).

Please reference as: McKay, J. and Devlin, M. (2015). "Low income doesn't mean stupid and destined for failure:" Challenging the deficit discourse around low SES students in higher education. International Journal of Inclusive Education. DOI: 10.1080/13603116.2015.1079273 
With a few recent exceptions (Gale 2011; Marshall and Case 2010; McKay and Devlin 2014; Smit 2012), students from low SES backgrounds are rarely recognised explicitly for the contribution that they make to higher education. This paper aims to contribute to addressing the absence in the higher education sector of that contribution. It draws on data to emerge from qualitative student and staff interviews to present evidence that challenges deficit conceptualisations of students from low SES backgrounds and recast them as potential assets to higher education.

\section{The study}

This paper emerges from a Commonwealth of Australia Office of Learning and Teachingfunded project on the effective teaching and support of students from low SES backgrounds in higher education. The project focused on effective approaches to teaching and supporting students who enter university with diversity in preparedness and in social and cultural capital. Concentrating on the student experience after enrolment, the project examined what helps these students succeed in higher education.

This study adopted a success-focused methodological approach; where "success" was defined as having completed one year of university study and re-enrolled for another year. It deliberately sought to focus on students from low SES backgrounds who had successfully negotiated and succeeded in their studies, and this was premised on the need to provide balance to the concentration in the extant research on the barriers facing these students. This methodological approach ensured we were able to unearth what helped students from low SES backgrounds succeed despite the challenges they face, which are well-documented. The theoretical approach to our study was drawn from Devlin's (2013) conceptual framework of "bridging sociocultural incongruity". Devlin (2013) claims neither institutions nor students are in deficit; rather; there is an existing sociocultural incongruity between middle-class higher education institutions and students from low SES backgrounds that needs to be bridged.

Success-focused, semi-structured qualitative interviews were conducted with 89 individual students from low SES backgrounds across three Australian universities. Initial screening for participant eligibility included: successful completion of at least one year of university study; a home address with a low SES postcode; and being the first in their generation of their family to attend university. Students were asked a series of questions about their perceptions about what had helped them to succeed, including teaching strategies, teachers and sources of support, among other factors. Interviews were also conducted with 26 teaching and support staff from six Australian universities. A high concentration of students from low SES backgrounds were a shared feature of the universities which participated in the study. Participants were identified by purposeful sampling of individuals identified as experienced and successful practitioners in the teaching and/or support of students from low SES backgrounds.

Please reference as: McKay, J. and Devlin, M. (2015). "Low income doesn't mean stupid and destined for failure:" Challenging the deficit discourse around low SES students in higher education. International Journal of Inclusive Education. DOI: 10.1080/13603116.2015.1079273 
Staff were asked a series of questions in relation to 'what works' in the teaching and support of students from this equity group. The transcripts of all interviews were analysed using qualitative computer software (NVivo 9), in which a general inductive approach of data analysis, delineated by Thomas (2006), was adopted. The findings underwent rigorous intercoder reliability and validity checks with a team of experienced researchers.

\section{"When learning gets ugly:" The impact of the deficit discourse}

Students from low SES backgrounds experience numerous challenges in higher education, and the barriers to their success are well documented. In the interviews with 26 staff members, a striking theme emerged relating to an "ugly" reality when staff made clear how deficit conceptualisations impact on teaching and learning. The quotes below from interviews with staff are confronting examples of attitudes toward students from low SES backgrounds that some Australian academics and general staff have encountered from their colleagues.

Low SES barbarians that need to be trained. [COL_007]

...you do sometimes hear about how lazy they are, how disengaged they are, how demanding they are. [COL_027]

...they can't hack it and they drop out. [COL_006]

Of course, these views are not representative of a large group, but their existence is importance to note. The data from the interviews indicated that there are situations where teachers and support staff can be 'particularly unhelpful, or discouraging' [STU_063], with 21 students ( 24 per cent), and 14 staff respondents (54 per cent) alluding to this issue. One student articulated their experience of asking questions of their lecturer:

I think being treated with some respect as an undergraduate student. I've been treated otherwise by lecturers, and I have left conversations, feeling perhaps not quite...worthwhile. [STU_063]

This same student spoke about the erroneous assumptions teachers often make:

I think it's easy for the lecturers to make assumptions about us. I recently had to call [a lecturer] ... She didn't bother to look up my details at all before she returned my call, and she was quite scathing toward me, and made a comment that I was now at university, not TAFE. I was left feeling fairly hurt by that comment. [STU_063]

Another student discussed how their teacher's lack of understanding affected them personally and academically:

..one teacher in particular ... I wasn't able to attend one of the classes because of work commitments, because I'm independent, like for other people work wouldn't be such a high priority ... but I need to live and I need to be there to study so it goes hand in hand, and this person wasn't very helpful. She kind of said "Well this isn't offered online, work it out yourself" sort of thing ... I got HD's in my two other classes and in the class that

Please reference as: McKay, J. and Devlin, M. (2015). "Low income doesn't mean stupid and destined for failure:" Challenging the deficit discourse around low SES students in higher education. International Journal of Inclusive Education. DOI: 10.1080/13603116.2015.1079273 
she taught, I got a credit, she ... just didn't seem like she wanted to help at all. [STU_006]

A staff member suggested that there seemed to be a 'wall between' students from low SES backgrounds and academic staff [COL_029], stemming from a lack of professionalism according to one student:

That's where the professionalism comes in. Perhaps the less experienced lecturers are still a bit like school children. They have their pets. They don't respect everyone in class ... but the professional teachers would treat us equally whether they like us or not [STU_085]

The challenges articulated by the students interviewed echo larger cultural problems that have been previously outlined by Appadurai (2004), whereby those from low SES backgrounds are diminished in dignity, inequality is perpetuated and lack of proper and fair access results. In this way, these issues are not just individual or institutional, but national (Appadurai 2004) (also see Alon 2009). Staff members certainly alluded to the cultural out-workings of this kind of treatment:

When you get a situation ... that is very uneven, and you've got Student A having massive academic self-esteem, and Student B having plummeting academic self-esteem, there's something not going right, and you could point to the program, but in my view ... you're probably more than likely to find the reason for that, in the actual personal and teaching skills of the actual educator involved. [COL_016]

I don't think they mean to be aggressive ... [but] that's absolutely damaging to anybody who's on that borderline of staying, not feeling secure and whatever. [COL_029]

Many students from low SES backgrounds have been educationally disadvantaged and, as a result, may encounter challenges in higher education. The problem however is when this becomes the collective view of all students from low SES backgrounds (Shields, Bishop and Mazawi 2005; Thomas 2013). As Smit (2012) warns, 'Not all students who come from academic disadvantage experience the same difficulties in higher education' (377). This was a major theme to emerge in our interviews. Staff in particular stressed the need for students from low SES backgrounds be valued for their unique experiences and challenges.

Find out what they damn well know before you start battering them. Don't start teaching and expect them to be ignorant. They'll have a rich experience. It mightn't be yours, but spend time figuring out what the students know. [COL_029]

Another staff member spoke about the barriers these students are up against in entering higher education and specifically, feelings of not belonging.

They've got the cultural sort of reasons for not going to university or not identifying with it ... They've been told, 'No sorry, stay out. You shouldn't be here'. So part of the job is to try and ... help students ... realise that they could give this a go. [COL_016]

Staff interviewed in the study urged others to be mindful of their preconceived ideas. One said:

Please reference as: McKay, J. and Devlin, M. (2015). "Low income doesn't mean stupid and destined for failure:" Challenging the deficit discourse around low SES students in higher education. International Journal of Inclusive Education. DOI: 10.1080/13603116.2015.1079273 
...don't make assumptions about the students. Even within any kind of category...[or] label, there is a diversity and wealth of experiences within that and what I worry about is that if you have the assumption that students are a particular way, that's how you teach them and I think you should always teach students with the expectation that they can excel and that they are capable and have capacity. [COL_008]

This sentiment resonates with Smit's (2012) critique of deficit thinking in the way it 'applies a narrow pathology-seeking assessment to groups of people and fails to recognise individual strengths' (377). Many staff interviewed stressed the point that the assumptions made about students from low SES backgrounds struggling academically are often erroneous:

My difficulty is that I don't think that it's necessarily the low SES students who are failing. [COL_011]

...there's a lot of myths around, oh these folk don't perform as well as others...generally it's not true, but it's a myth that's out there. [COL_028]

Staff were emphatic in countering existing stereotypes and myths:

...students who came from public high schools tended to do better and last longer and succeed faster ... than students who came from private schools...[COL_013]

... stats have shown in our course that generally speaking our low SES students tend to do better. They're slightly better motivated and probably more capable students. [COL_014]

Out of 26 interviewees, 14 staff members (54\%) commented on the deficit conceptualisation of these students and its negative impact on students. One example of this is the failure of teachers to notice high achieving students from low SES backgrounds.

I think sometimes there's so much focus on the students that may be struggling that we forget that maybe the students at the other end as well that little bit of extra encouragement might just give them the chance to go even further.

The need to debunk deficit conceptions of these students is further supported by the finding that 24 out of 26 staff interviewed (92\%) stated that valuing and respecting students from low SES backgrounds was a key factor in their success. A significant aspect of respecting students lies in actively embracing the contribution that they make to higher education:

So I'm very strongly in favour of people just embracing it [diversity] and trying to get as many different voices coming into the mix as possible. [COL_013]

I think people understand what the benefits are, we talk about the diversity of students and the importance of having all these cohorts but I don't know if we talk about the benefits enough. [COL_028]

\section{The contribution that low socioeconomic students make to higher education}

The data from the staff and student interviews challenge the assumption that a low SES background is synonymous with low standards and academic struggle and failure. Contrary to Please reference as: McKay, J. and Devlin, M. (2015). "Low income doesn't mean stupid and destined for failure:" Challenging the deficit discourse around low SES students in higher education. International Journal of Inclusive Education. DOI: 10.1080/13603116.2015.1079273 
the view that these students are in deficit, the qualitative data indicate a picture of these successful students as determined and persistent, actively seeking academic challenges and exhibiting high-level academic skills (also see Bowden and Doughney 2010; Marshall and Case 2010; Devlin et al. 2012).

\section{Determination and persistence}

One of the key findings to emerge was the determination that the students from low SES backgrounds featured in our study exhibited in relation to their university studies. Research testifies to their many challenges, which include: financial pressures and constraints (Simister 2011; David, Crozier, Hayward et al. 2010; Greenbank 2006); the need to balance paid work, families and carer duties with study (Murphy 2009; Henderson et al. 2009; Benson et al. 2009); lacking support networks and structures (Hahs-Vaughn 2004); low confidence levels and self-esteem (Benson et al. 2009; Lawrence 2005); an incongruity in the cultural capital they bring with them into middle class higher education institutions (Devlin 2013; Greenbank 2006); and a lack of familiarity with university level academic skills, discourses and practices (Smit 2012). Against the backdrop of this literature and the challenges and obstacles that these students face in attending, progressing through and succeeding at university, their determination and persistence is remarkable.

Staff noted the exceptional level of determination and/or persistence that these students showed to overcome these challenges:

I just think it's very interesting that we often look at low SES [students] and sort of go 'Okay...they're not going to have the study skill management or the time skill management, they're the first one in their family to go to university, they're not going to understand all the rigour and the words and all the rest' but then I look at them and go, 'Well, actually, a lot of these kids are determined to be here and they're determined to work harder and they're determined to finish. And they're going to ask a question if they don't know because there's nobody else to tell them'... whereas other kids who sort of have been spoon fed will look at it and go 'Well, you didn't tell me to do anything else so I didn't'. [COL_013]

One staff member urged others to offer support as these students learn the systems, practices and processes of higher education:

They're very smart and determined people and it takes them a couple of years to nut out the system but if you are halfway welcoming they can do it very quickly. [COL_007]

They've got the determination, they've got the will, and they've got the interest.[COL_016]

The evidence above challenges deficit conceptualisations of these students as "lacking" by indicating that they have the will and determination to succeed. It also supports claims by Marshall and Case (2010) that experiences of disadvantages can translate to these students bringing valuable 'resources into higher education, and...mobilis[ing] them towards personal growth and academic success' (501). These students can thus be advantaged by their

Please reference as: McKay, J. and Devlin, M. (2015). "Low income doesn't mean stupid and destined for failure:" Challenging the deficit discourse around low SES students in higher education. International Journal of Inclusive Education. DOI: 10.1080/13603116.2015.1079273 
"disadvantage", in that they can possess experience and coping mechanisms that their more privileged peers may not (Marshall and Case 2010).

Fifty-six of the 89 students interviewed (63\%) attributed their success to being determined to apply themselves and work hard. They spoke of their high aspirations, and desire to rise above their circumstances.

My desire has kept me on focus. I want that piece of paper. [STU_066]

I guess my own dedication ... has been a big factor...I have been quite dedicated...to achieve high results... [STU_041]

I want that cap and gown, and I want someone to call my name out. [STU_062]

When asked about what had helped them to succeed, one student articulated the competing pressures they faced and how their determination to succeed had gotten them through:

I think my determination not to give up. I think I had a goal in mind when I first started and I knew it was going to be difficult given that I have small children and I do work full time ... but I do strive to do something with my studies everyday ... it's just been a matter of ... being persistent ... Because it would be very easy to give up ... but I'm not going to do that. [STU_046]

Students also alluded to the impact their financial constraints had on their attitude and determination to succeed:

I always had in my mind that paying money to go to university, that I wasn't just going to be there just to get a pass. That would have been pointless if I was paying hundreds of dollars to attend these classes. I was going to give it my best shot and get the best marks that I possibly could. [STU_035]

Such views are particularly powerful when the context of financial hardship and competing pressures are considered. Students' determination to do well and succeed was a recurring trend in the data. These findings echo those in previous studies which similarly found some students from low SES backgrounds are determined to succeed and demonstrate considerable resilience and persistence despite the many 'inequalities they face' (Perry and Francis 2010, 8) (also see Crozier and Reay 2008; Crozier et al. 2009).

\section{Academic Challenge}

Contrary to the view that students from low SES backgrounds are the cause of decreasing standards and the "dumbing down" of courses (Leathwood and O'Connell 2003), student respondents conceptualised themselves as high achievers actively seeking academic challenges. One noted:

I have so many of my friends say, "Oh, yeah. All I need is a pass and I just want to get a pass." But I want more than that... [STU_002]

Please reference as: McKay, J. and Devlin, M. (2015). "Low income doesn't mean stupid and destined for failure:" Challenging the deficit discourse around low SES students in higher education. International Journal of Inclusive Education. DOI: 10.1080/13603116.2015.1079273 
Other students shared this attitude:

I want to do good at it... if I'm going to do something, I want to do it well. I don't just want to scrape together a thousand words and hope it passes. [STU_087]

Well, you just got to put in effort. You've got to - it's none of this high school stuff, leaving it to the very last day and then doing it...You've just got to get in and put in an effort, research it, take initiative and responsibility, and just get in and do it and put your best and don't do sort of, "Oh, I'll just do a half job and that'll be fine." You can't have that attitude at university. You've got to put in your best. [STU_044]

Other students explained how their choice of subjects was based on those that posed an academic challenge:

I remember taking my three subjects in first year. I chose the most difficult ...to begin with and ...that...really gave me the motivation to study and keep on with it. [STU_103]

Staff interviewed agreed with the need to maintain high academic standards, stressing that the common assumptions made about students from low SES backgrounds and associated lower standards were unfounded. One staff member was keen to foreground that these students are high achieving and at least equally determined to do as well as more traditional student cohorts. She spoke of one low SES student: 'I had someone who got High Distinctions, who came to see me to be better.' Another explained:

...it's about flexibility and responsiveness to a person's situation and thinking about what is the contextual factors around them that are impacting on their ability to meet all the demands of the course [COL_009].

Such evidence challenges views that often appear in the literature. For example, a recent study by Perry and Francis (2010) in the UK found that 'Social class remains the strongest predictor of educational achievement' (2). Meanwhile, in the US, a gap of up to four years has been found to exist between wealthy students and those from low SES backgrounds (Riddle 2014). Uncritically accepting that 'Children who come from low socioeconomic backgrounds are more likely to have low educational attainment' (Riddle, 2014, 3) may lead to assumptions about all students from low SES backgrounds about which university educators need to be aware.

One staff member in the study insisted that maintaining high academic standards relies on educators who 'reinforce success' [COL_023], while another claimed such maintenance depends on students not being 'molly coddled' but instead given 'support as required, which...[is] equity really, isn't it?' [COL_024]. Haggis (2006) found that although some learners "may enter higher education with a history of "low achievement", this is not necessarily related to their capacity' (527). The findings of the study demonstrate that with the right support, low SES university students are enabled to succeed and to attain high standards. Maintaining the appropriate standards must thus be a collaborative effort between

Please reference as: McKay, J. and Devlin, M. (2015). "Low income doesn't mean stupid and destined for failure:" Challenging the deficit discourse around low SES students in higher education. International Journal of Inclusive Education. DOI: 10.1080/13603116.2015.1079273 
educators and these students who both want and seek high academic standards for themselves (McKay and Devlin 2014).

\section{Academic skills and behaviours}

Murphy (2009) and Northedge (2003) respectively, point to an assumption that exists in higher education that students from low socioeconomic backgrounds have lower levels of academic preparedness to those of traditional students. Such assumptions may work to ensure that students from low SES backgrounds are 'persistently regarded as problematic learners and potential drop-outs' (Perry and Francis 2010, 8). These students are also often viewed as not being equipped with the skill-set of more traditional students in terms of their academic, research, computer, writing and language skills (Kirk 2008; Fitzgibbon and Prior 2006). Smit (2012) views these concerns with levels of academic preparedness as understandable given that many 'non-traditional' students do indeed enter higher education with gaps in their skills and conceptual knowledge as a result of inadequate schooling and disadvantage. However, in her recent work challenging deficit thinking, Smit (2012) claims, "“disadvantage" has become an umbrella term to cover a wide array of perceived shortcomings and has not been clearly conceptualised' (370).

Despite the sociocultural incongruity between students from low SES backgrounds and the middle class environment of higher education institutions (Devlin 2013; Greenbank 2006), the study found that given the right support, many of these students were active agents in their own learning and achievement, exhibiting high levels of the following academic skills and behaviours: independence; help-seeking; planning ahead; goal setting; and time management.

\section{Independent learning}

Independent learning is an objective for all students in higher education (Spiro, Henderson and Clifford 2012). According to Smit (2012), inherent in the concept of autonomous learning is an expectation that 'students will take full responsibility for their studies' as well as 'a vehement aversion to the idea of "spoon-feeding" students' (3). The deficit thinking surrounding students from low SES backgrounds can result in a failure to conceive of them as independent learners, and they can be viewed as students in need of the maligned "spoonfeeding" approach. Contrary to this view, staff noted the resourcefulness of students from low SES backgrounds:

So students [from low SES backgrounds] tended to do better and last longer and succeed faster... simply because they never had the resources handed to them and they always had to fight for everything and they were much more independent learners. [COL_013]

So there's research that suggests that people from low SES and sort of high schools in particular [where] this research was done, actually are more independent learners. They don't require as much handholding and resource management because they've never had

Please reference as: McKay, J. and Devlin, M. (2015). "Low income doesn't mean stupid and destined for failure:" Challenging the deficit discourse around low SES students in higher education. International Journal of Inclusive Education. DOI: 10.1080/13603116.2015.1079273 
that and they've always been go-getters and that's why they've actually come to university because they're able to do this for themselves. [COL_013]

Students similarly spoke of themselves as independent learners:

And also with uni, it facilitates independent learning. So I can work out the best way that I learn and then apply that to my studies. [STU_074]

...once you get to university, you realise it's a completely different system to high school. And you ... are not forced to do subjects and ... nothing is forced. It's all up to you. [STU_003]

I guess I was just more of an independent learner right from the start and tended not to seek out extra help. [STU_007]

I suppose the thing that really helped me get through my uni studies is the fact that I'm ... an independent learner ... I take active responsibility for the things that I learn and need to know and especially for my success. [STU_103]

In the age of increasing diversity, current framings of independent learning and learner responsibility are being called into question (Northedge 2003). Haggis (2006), for example, argues that expectations about autonomy and independent study are rarely made explicit or explained to students. In order for these students to develop independent learning skills, Haggis (2006) stresses the need for expectations to be clearly articulated to students who may require initial, early support in this area. While the students we interviewed were autonomous in their learning, a significant part of being independent learners depends on educators and support staff articulating expectations around independent learning (Devlin et al. 2012; Haggis 2006).

\section{Help-seeking behaviour}

Students spoke about themselves as active agents in their learning and they were quick to identify when they required help and where to seek that help.

I think it's all about personally becoming engaged in these services, and...there are a lot of services, but you have to be willing to go and find them, and ask for help ... I really did try and access everything I could. [STU_057]

...doing it yourself and ... seeking help when you need it, but not relying on anybody else. [STU_004]

These quotes point to the agency of these students not often noted in the literature or anecdotally. Overlooking their agency is a significant corollary of the deficit discourse. Shields, Bishop and Mazawi $(2005,127)$ posit that, 'One of the most damaging expressions of pathologizing through education is the negation of agency'.

Staff similarly spoke about the need for 'building student agency and responsibility in their own learning' [COL_029]. Many staff found students from low SES backgrounds as more

Please reference as: McKay, J. and Devlin, M. (2015). "Low income doesn't mean stupid and destined for failure:" Challenging the deficit discourse around low SES students in higher education. International Journal of Inclusive Education. DOI: 10.1080/13603116.2015.1079273 
active in their learning and help-seeking than high SES students who were more accustomed to having assistance and resources handed to them.

\section{Time management, planning ahead}

Students from low SES backgrounds are often "time poor" (Devlin et al. 2012) as a result of balancing financial pressures, family responsibilities, and greater hours of paid employment with study (Murphy 2009; Henderson et al. 2009; Benson et al. 2009; Northedge 2003). Forty-five students $(51 \%)$ from the sample attributed their overall success in their studies to their time management skills.

I know when my exams are, I know when my assignments are due right from the very beginning, so I can plan everything around the three kids.[STU_054]

I've got a diary where I've actually blocked out specific days, specific times that I'm just going to dedicate to my uni studies and then I've made sure that I've stuck to those times. I've also let family and friends know, during these times...I'm not available.[STU_026]

The more organised and time that's set aside the better the marks seems to be. But I suppose it's just finding that time when you're obviously not doing just university. So, for example, work and children and all the rest of it.[STU_034]

While the students we interviewed were agentive in their learning practices, Smit (2012) warns against the responsibility for learning being put on the student alone. She is equally mindful of not placing the responsibility on institutions and the structures they have in place. Instead, Smit argues for a 'balance between the agency of the student being and the structures bearing on the student' (376).

The majority of students interviewed demonstrated these academic skills and behaviours, however with its focus on "success" this study did not pick up those students who are struggling with their independent learning, help-seeking and time management. The problem, according to Haggis (2006), is that these academic behaviours, which are so valued in higher education, are often not made explicit to students who may not enter university with a familiarity with academic systems and practices. She explains, 'What is potentially difficult...is that these underlying principles are usually only implicit...and are therefore difficult for those unfamiliar with the discourse to see and understand' $(2006,524)$. Further, this is not to suggest that students from more traditional backgrounds do not also exhibit the above traits. But considering the literature around students from low SES backgrounds, these findings proffer a challenge to the deficit conception of these students.

\section{Conclusion}

In Australia, issues of class and the need for a dialogue about deficit conceptions is made problematic as there is a purported taboo around talking about social class (Riddle 2014). Regardless of the potential awkwardness, the "logics of power" (Thomson 2008) at play in

Please reference as: McKay, J. and Devlin, M. (2015). "Low income doesn't mean stupid and destined for failure:" Challenging the deficit discourse around low SES students in higher education. International Journal of Inclusive Education. DOI: 10.1080/13603116.2015.1079273 
institutions and how this impacts those who are positioned as "other" upon entry to higher education needs consideration. It is only by changing the 'environments, discourses, attitudes, positionings, and relationships' within higher education institutions, that it becomes possible to create conditions under which all students are empowered to achieve and succeed (Shields, Bishop and Mazawi 2005, 142) (also see Gonski 2011). This paper has argued for the need to challenge the deficit discourse around students from low SES backgrounds to ensure they are empowered to succeed. It elucidates the range of attendant issues stemming from the deficit discourse and urges for a more nuanced conceptualisation of students from low SES backgrounds students in higher education — one that recognises the contribution they make to higher education. Contributing to a more positive view of these students, it demonstrates that they are hard-working, high achieving, and determined to succeed. Moreover, the findings in this paper articulate and highlight the dangers of prejudging a student's academic potential based on their SES status; the importance of having high expectations for all students; and the necessity to remember that all students from diverse backgrounds should be valued for the potential contribution they can bring to other students and to higher education.

In accordance with Smit (2012), this paper acknowledges that there are no easy solutions to helping students from low SES backgrounds succeed in higher education. The authors are also mindful of oversimplifying what is a far from simple issue (Boughey 2002), and recognise that one limitation (however purposeful) of its approach has been to focus entirely on those students from low SES backgrounds considered "successful". However, transcending the "type" of students we have focused on, deficit conceptualisations-whether at the institutional or classroom level - of students from low SES backgrounds do not benefit either students or institutions. In their failure to serve any benefit, they are no longer useful in the changing higher education landscape. They need to be overhauled in favour of a more dynamic approach to these students; one that recognises the complexities of the issue and the challenges these students face in and out of the academe. Smit (2012) insists that diversity needs to be valued and institutions need to strive to tap "into its riches", Gale (2011) calls for "recognition of difference", Haggis (2006) proposes a "change of perspective", while Scott et al. (2007) suggest diversity be seen as "enriching".

What is required is a fundamental rethink of the way students from low SES backgrounds are conceptualised and subsequently treated. To change deficit thinking, a more nuanced, complex non-deficit approach is needed (Bok 2010). It requires a shift from 'non-agentic and oppressive theorizing to agentic and empowering theorizing and positionings that acknowledge and promote self-determination' (Shields, Bishop and Mazawi 2005, xx) to ensure that the current deficit view of low SES groups is overcome. This paper provides evidence that supports a more affirmative conception of students from low SES backgrounds - one that recognises their agency and capacity — and the contributions they make to higher education.

Please reference as: McKay, J. and Devlin, M. (2015). "Low income doesn't mean stupid and destined for failure:" Challenging the deficit discourse around low SES students in higher education. International Journal of Inclusive Education. DOI: 10.1080/13603116.2015.1079273 


\section{References}

Alon, S. (2009). The evolution of class inequality in higher education competition, exclusion, and adaptation. American Sociological Review, 74 (5), 731-755.

Appadurai, A. (2004). The capacity to aspire: Culture and the terms of recognition. In V. Rao and M. Walton (eds.), Culture and public action, 59-84. Stanford, CA: Stanford University Press.

Archer, L. (2007): Diversity, equality and higher education: a critical reflection on the $\mathrm{ab} / \mathrm{uses}$ of equity discourse within widening participation, Teaching in Higher Education, 12 (5-6), 635-653.

Benson, R., Hewitt, L., Devos, A., Crosling, G. and Heagney, M. (2009). Experiences of students from diverse backgrounds: The role of academic support, in The Student Experience. Proceedings of the 32nd HERDSA Annual Conference, Darwin, 6-9 July 2009, 545-550.

Bishop, R., and Glynn, T. (2003). Culture counts: Changing power relations in education. Zed Books.

Bok, J. (2010). The capacity to aspire to higher education: 'It's like making them do a play without a script'. Critical Studies in Education, 51 (2), 163-178.

Boughey, C. (2007). Marrying equity and efficiency: The need for Third generation academic development. Perspectives in Education, 25 (3): 27-38.

Bowden, M. P. and Doughney, J. (2010). Socio-economic status, cultural diversity and the aspirations of secondary students in the Western Suburbs of Melbourne, Australia. Higher Education, 59 (1), 115-129.

Clare, J. (1999). £100m university bonus ‘will lead to dumbing down’, The Daily Telegraph, 5 March.

Commonwealth of Australia 2010. Higher Education Support Act 2003: Other grants guidelines (Education) 2010. Canberra: Commonwealth of Australia.

Department of Education 2013. Selected Higher Education Statistics - 2013 Student Data. https://education.gov.au/selected-higher-education-statistics-2013-student-data.

Devlin, M., McKay, J., Kift, S., Nelson, K., Smith, L. (2012). Effective teaching and support of students from low socioeconomic backgrounds: Resources for Australian higher education, Final Report. Available at http://www.lowses.edu.au.

Devlin, M. (2013). Bridging socio-cultural incongruity: Conceptualising the success of students from low socio-economic status backgrounds in Australian higher education. Studies in Higher Education, 38 (6), 939-949.

Dibben, N. (2006). The socio-cultural and learning experiences of music students in a British university. British Journal of Music Education, 23 (01), 91-116.

Fitzgibbon, K. and Prior, J. (2006). Students' early experiences and university interventions: A timeline to aid undergraduate student retention. Widening Participation and Lifelong Learning, 8(3).

Ford, D. Y., Harris III, J. J., Tyson, C. A., and Trotman, M. F. (2001). Beyond deficit thinking: Providing access for gifted African American students. Roeper Review, 24 (2), 52-58.

Furedi, F. (2004). Where Have all the Intellectuals Gone: Confronting 21st Century Philistinism.

UK: Continuum International Publishing

Gale, T. (2011). Expansion and equity in Australian higher education: three propositions for new relations. Discourse: studies in the cultural politics of education, 32 (5), 669-685.

Please reference as: McKay, J. and Devlin, M. (2015). "Low income doesn't mean stupid and destined for failure:" Challenging the deficit discourse around low SES students in higher education. International Journal of Inclusive Education. DOI: 10.1080/13603116.2015.1079273 
Gonski, D. M. (2011). Review of funding for schooling: Final report. Australia: Department of Education, Employment and Workplace Relations.

Greenbank, P. (2006). Institutional widening participation policy in higher Education: dealing with the issue of social class. Widening Participation and Lifelong Learning, 8(1).

Haggis, T. (2006). Pedagogies for diversity: Retaining critical challenge amidst fears of 'dumbing down'. Studies in Higher Education, 31 (5), 521-535.

Hahs-Vaughn, D. (2004). The impact of parents' education level on college students: An analysis using the Beginning Postsecondary Students Longitudinal Study 1990-92/94. Journal of College Student Development, 45 (5), 296-316.

Hayes, D. (2003) New labour, new professionalism, in J. Satterthwaite, E. Atkinson and K. Gale (eds.), Discourse, power, resistance: challenging the rhetoric of contemporary education, Stoke-on-Trent: Trentham Books.

Henderson, R., Noble, K. and De George-Walker, L. (2009). Transitioning into university: 'Interrupted' first year students problem-solving their way into study. Studies in Learning, Evaluation, Innovation and Development, 6 (1): 51-64.

James, R. (2002). Students' changing expectations of higher education and the consequences of mismatches with reality. Responding to Student Expectations. Paris: OECD.

Kirk, K. (2008). Diversity and achievement: Developing the learning of non-traditional HE Students. In Crosling, G., Thomas, L. and Heagney, M. Improving student retention in higher education: The role of teaching and learning. Oxford: Routledge, 150-159.

Leathwood, C. and O'Connell, P. (2003). 'It's a struggle': the construction of the 'new student' in higher education. Journal of Education Policy, 18 (6), 597-615.

Margison, J. A. (2008). Recent Dissertation Research in Gifted Studies. Roeper Review, 30 (3).

Marshall, D., and Case, J. (2010). Rethinking 'disadvantage' in higher education: A paradigmatic case study using narrative analysis. Studies in Higher Education, 35 (5), 491-504.

McKavanagh, M., and Purnell, K. (2007). Student learning journey supporting student success through the student readiness questionnaire.

McKay, J. and Devlin, M. (2014). "Uni has a different language...to the real world:" Demystifying academic culture and discourse for students from low socioeconomic backgrounds. Higher Education Research and Development. doi:10.1080/07294360.2014.890570.

Morales, E. E. (2000). A contextual understanding of the process of educational resilience: High achieving Dominican American students and the "resilience cycle". Innovative Higher Education, 25 (1), 7-22.

Murphy, B. (2009). Great expectations? Progression and achievement of less traditional entrants to higher education. Widening Participation and Lifelong Learning, 11 (2): 414.

Northedge, A. (2003). Enabling participation in academic discourse, Teaching in Higher Education, 8 (2), 169-180.

Perry, E. and Francis, B. (2010). The social class cap for educational achievement. RSA Projects, December, 2.

Pitman, T. 2014. 'More students in higher ed, but it's no more representative', The Conversation, 28 July, 1-4.

Quinn, J. (2004). Understanding working-class 'drop-out' from higher education through a sociocultural lens: Cultural narratives and local contexts. International Studies in Sociology of Education, 14(1), 57-74.

Please reference as: McKay, J. and Devlin, M. (2015). "Low income doesn't mean stupid and destined for failure:" Challenging the deficit discourse around low SES students in higher education. International Journal of Inclusive Education. DOI: 10.1080/13603116.2015.1079273 
Reay, D., David, M. E., and Ball, S. J. (2005). Degrees of Choice: Class, Gender and Race in the Higher Education choice process. London: Trentham Books.

Riddle, S. (2014). 'Why poor kids continue to do poorly in the education game', The Conversation, 4 March, 1-4. Available at: http://theconversation.com/why-poor-kidscontinue-to-do-poorly-in-the-education-game-23500.

Smit, R. (2012). Student voice in 'the transition to university' problem. Conference paper, presented at the ASSAF (Academy of Science of South Africa) Mind The Gap Forum, $1-6$.

Shields, C. M., Bishop, R., and Mazawi, A. E. (2005). Pathologizing practices. Lang.

Spiro, J., Henderson, J., \& Clifford, V. (2012). Independent learning crossing cultures: learning cultures and shifting meanings. Compare: A Journal of Comparative and International Education, 42 (4), 607-619.

Susanti, D. 2011. Privatisation and marketisation of higher education in Indonesia: The challenge for equal access and academic values. Higher Education 61 (2), 209-218.

Swadener, B. and Lubeck, S. (eds.) (1995). Children and families "at promise". Deconstructing the discourse of risk, Albany: SUNY Press.

Swanson, D. (2002). "Disadvantage" and School Mathematics: The Politics of Context. International Journal of Learning, 9: 1471-80.

Teese, R., and Polesel, J. (2003). Undemocratic schooling: Equity and quality in mass secondary education in Australia. Melbourne, Australia: Melbourne University Publishing.

Thomas, D. R. (2006). A general inductive approach for analyzing qualitative evaluation data. American journal of evaluation, 27(2), 237-246.

Tinto, V. (2003). Learning better together: The impact of learning communities on student success. Higher Education, Monograph series, 1(8).

Thomson, P. 2008. Field. In M. Grenfell (ed). Pierre Bourdieu: Key Concepts, (67-84). Stocksfield, UK: Acume.

Vuong, M., Brown-Welty, S. and Tracz, S. 2010. The Effects of Self-Efficacy on Academic

Success of First-Generation College Sophomore Students. Journal of College Student Development, 51 (1), 50-64.

Wagstaff, L.H., and Fusarelli, L.D. (1995). Governance structures in effective schools: A review of the literature. Austin, TX: The University of Texas.

Webb, S. (1997) Alternative students? Conceptualizations of difference, in J. Williams (ed.) Negotiating Access to Higher Education: the discourse of selectivity and equity, Buckingham: SRHE and the Open University Press, 65-86.

Western, J., McMillan, J. and Durrington, D. (1998), Differential Access to Higher Education: The measurement of socioeconomic status, rurality and isolation, Report submitted to the Evaluations and Investigations Programme, Department of Employment, Education, Training and Youth Affairs, June.

Valencia, R.R. (ed.). (1997). The evolution of deficit thinking: Educational thought and practice (Vol. 19). Psychology Press.

\section{Word count: 7981 words}

Please reference as: McKay, J. and Devlin, M. (2015). "Low income doesn't mean stupid and destined for failure:" Challenging the deficit discourse around low SES students in higher education. International Journal of Inclusive Education. DOI: 10.1080/13603116.2015.1079273 